\title{
Influenza infection and heart failure - vaccination may change heart failure prognosis?
}

\author{
Nikolaos P. E. Kadoglou ${ }^{1,2}$ • Frank Bracke ${ }^{1} \cdot$ Tim Simmers $^{1} \cdot$ Sotirios Tsiodras $^{3}$. \\ John Parissis 4
}

Published online: 15 May 2017

(C) The Author(s) 2017. This article is an open access publication

\begin{abstract}
The interaction of influenza infection with the pathogenesis of acute heart failure (AHF) and the worsening of chronic heart failure (CHF) is rather complex. The deleterious effects of influenza infection on AHF/CHF can be attenuated by specific immunization. Our review aimed to summarize the efficacy, effectiveness, safety, and dosage of anti-influenza vaccination in HF. In this literature review, we searched MEDLINE and EMBASE from January 1st 1966 to December 31st, 2016, for studies examining the association between $\mathrm{AHF} / \mathrm{CHF}$, influenza infections, and anti-influenza immunizations. We used broad criteria to increase the sensitivity of the search. HF was a prerequisite for our search. The search fields used included "heart failure," "vaccination," "influenza," "immunization" along with variants of these terms. No restrictions on the type of study design were applied. The most common clinical scenario is exacerbation of preexisting CHF by influenza infection. Scarce evidence supports a potential positive association of influenza infection with AHF. Vaccinated patients with pre-existing CHF have reduced allcause morbidity and mortality, but effects are not consistently documented. Immunization with higher antigen quantity may confer additional protection, but such aggressive approach has
\end{abstract}

Nikolaos P. E. Kadoglou

nikoskad@yahoo.com

1 Department of Cardiology, Catharina Hospital, Michelangelolaan 2, 5623 EJ Eindhoven, The Netherlands

2 Centre for Statistics in Medicine-Botnar Research Centre, University of Oxford, Oxford, UK

3 4th Department of Internal Medicine, Attikon University Hospital, Athens, Greece

4 Heart Failure Unit, Department of Cardiology, Attikon University Hospital, Athens, Greece not been generally advocated. Further studies are needed to delineate the role of influenza infection on AHF/CHF pathogenesis and maintenance. Annual anti-influenza vaccination appears to be an effective measure for secondary prevention in HF. Better immunization strategies and more efficacious vaccines are urgently necessary.

Keywords Influenza infection $\cdot$ Heart failure ·

Decompensation · Mortality $\cdot$ Hospitalization · Dose ·

Vaccination $\cdot$ Immunization

\section{Influenza infection and heart failure}

\section{Influenza infection burden}

Influenza is a respiratory RNA virus with two types, A and B, causing epidemic human disease in a seasonal pattern [1]. Based on surface antigens (e.g., hemagglutinin, neuraminidase), influenza virus type $\mathrm{A}$ is further classified into subtypes [2]. Immunity to surface antigens protects individuals against infection from one influenza virus type or subtype but confers little or no immunity against other types and subtypes. Frequent mutations in haemagglutinin and neuramidase antigens (antigenic drift) create new variants circumventing existing immunity in a partial or complete way. In cases of antigenic drift influenza strains are more likely to cause seasonal epidemics [3] with limited coverage by circulating vaccines prepared well in advance from the annual seasonal epidemic.

In the absence of a global anti-influenza vaccine conferring permanent immunity, influenza remains one of the leading causes of widespread viral diseases, with high morbidity and mortality. An estimated $5-10 \%$ of adults and $20-30 \%$ of children are infected by influenza worldwide, while 250,000 
500,000 severely infected individuals are estimated to die annually [4].

The association between influenza and cardiovascular morbidity and mortality is confounded by several factors. Firstly, significant under-testing and under-diagnosis occurs in affected patients. Point-of-care molecular testing is becoming gradually widely available with emphasis on specificity during the influenza season and on sensitivity outside it [5]. Secondly, influenza infections impact may vary according to virus type, duration of circulation, the prevalence of "high risk" population groups, including the elderly and patients with other besides cardiac disease, chronic co-morbidities (e.g., chronic lung disease, diabetes mellitus, cancer, etc.) and underlying herd immunity/immunization defects [6]. Thirdly, most influenza-related deaths are frequently under-reported, because influenza often exacerbates underlying diseases, i.e., cardiac disease that may be recorded as the primary cause of death [7]. Thus, the number of influenza-related deaths is often monitored as the number of excess deaths compared to a period without known influenza viruses' activity [8]. Similarly, there is increased occurrence of bacterial co-infections, i.e., pneumonia, meningitis, in the course of influenza infection [9], overlapping the influenza viruses' impact.

Thus, a wide-spectrum of influenza-related consequences can be seen in patients with chronic disease including cardiac patients ranging from uncomplicated recover within 1 week of illness without requiring any medical intervention to a severely ill patient requiring intensive care unit treatment. Statistical modeling methods and health system records have estimated a high annual burden of influenza-attributable hospitalizations and deaths resulting in a significant strain on national health systems and substantial economic loss [10].

\section{Methods of literature search}

The aim of the present clinical review was to evaluate the literature about the efficacy, effectiveness, safety, and dosage of anti-influenza vaccination in HF patients. A search was conducted for English language publications in MEDLINE and EMBASE databases from January 1st 1966 to December 31st, 2016. The following broad search terms, including Medical Subject Headings (MeSH), were used: chronic heart failure (CHF), acute heart failure (AHF), acute decompensated heart failure (ADHF), influenza infection, vaccination, immunization, hospitalizations, mortality, death, and heart failure decompensation. Two investigators (NK and ST) performed the literature research. With the exception of case studies, all other study designs were considered (both randomized and non-randomized), whether prospective or retrospective. We excluded studies that did not report heart failure outcomes. The reference list of the included articles was checked to identify other relevant papers for inclusion.
Interaction of influenza infection with acute and chronic heart failure development

Numerous observational studies have shown an elevated risk for acute cardiovascular events (e.g., stroke, acute myocardial infarction-AMI,) in general population, not only within the first few days of infection [11-13], but also in the long term (>30 days) [11].

Influenza infection and development of chronic heart failure It is still obscure whether influenza infection can be a primary cause of heart failure (HF). A wealth of information implicates the involvement of inflammatory activation in the development and progression of CHF [14]. Nevertheless, a pure causative association between infection and both AHF and CHF development is still elusive. Influenza infection may induce acute, direct myocardial dysfunction through the stimulation of immune system and inflammation [15, 16]. This derives from histologically evident direct myocardial injury, myocarditis, and myocyte necrosis (found in myocardial tissue samples after influenza-related deaths). In addition to this, the high metabolic demands, and potent inflammatory and thrombotic agents activated by infection may indirectly suppress myocardial function leading to either new onset $\mathrm{HF}$ or acute decompensation of chronic HF (see below). Proinflammatory cytokines release, endothelial dysfunction, and sympathetic activation comprise the common pathophysiologic mechanisms of HF [14]. Influenza accompanied by changes in cardio-renal function may exaggerate fluids shift, leading to volume overload and hence HF development, progression, or decompensation [17, 18]. Unfortunately, all the above mechanistic explanations are still speculative and to our knowledge, no studies have ever shed light on the pathophysiologic interference between new onset HF and influenza infection, as well as the potential protective effect of antiinfluenza vaccination (Fig. 1).

Influenza infection and development of acute decompensated heart failure (ADHF) Infection-induced ADHF may develop on the top of pre-existing HF, already diagnosed or not $[19,20]$. A significant indication of the interaction between ADHF and influenza comes from the parallel fluctuations of HF-related hospitalizations and seasonal infections like influenza [21]. Indeed, long-term monitoring of USA population showed the peak of hospitalizations due to ADHF during winter and the lowest curve during summer. The seasonal variation of ADHF-related morbidity and mortality has been also mentioned in numerous, national-based cohort studies [21-23]. This is reasonable since patients with HF appear with limited cardiac and respiratory reserves are older and unable to tolerate infection-induced cardiac compromise. In those frail patients with CHF, the elaboration of proinflammatory and oxidative mediators may easily lead to 


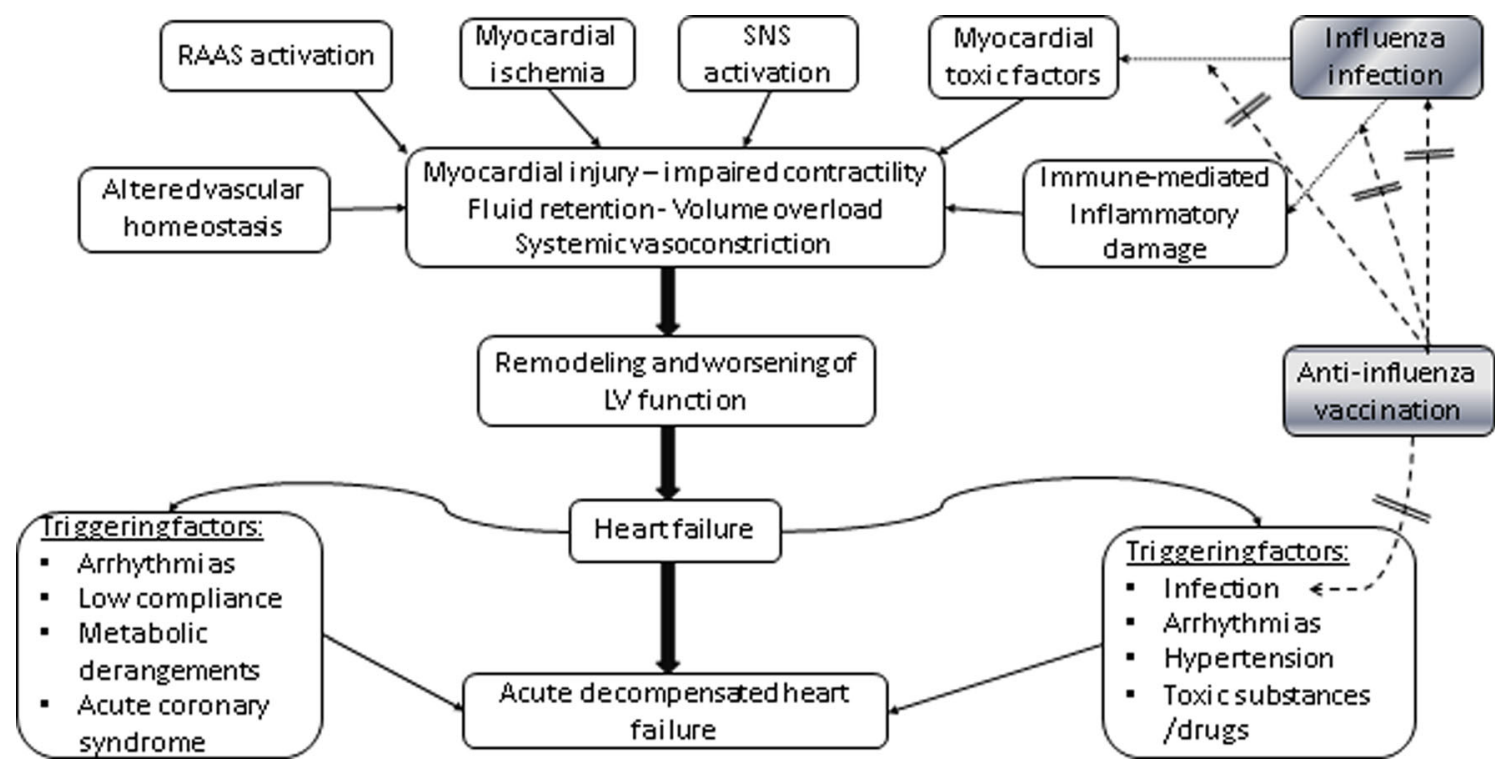

Fig. 1 Pathophysiologic mechanisms of chronic heart failure development and its acute decompensation. The potential preventive effect of antiinfluenza vaccination. $R A A S$ renin-angiotensin-aldosterone system; $S N S$ sympathetic nervous system, $L V$ left ventricle

ADHF [24]. Moreover, the pre-existed vascular congestion may mechanically induce endothelial activation triggering an acute decompensation $[25,26]$. On the other hand, influenza infection highly predisposes to stimulation of all the latter mechanisms. Thereby, the co-existence of HF and influenza may easily lead to the detrimental ADHF $[11,21]$.

\section{Anti-influenza vaccination and heart failure}

\section{Anti-influenza vaccination and cardiac diseases}

Immunization against seasonal influenza has risen during the last decades as a potential measure to reduce hospitalization rate $[27,28]$ and all-cause mortality among elderly subjects [29-31] during influenza epidemics. Community-based studies support the preventive effectiveness of anti-influenza vaccination on cardiovascular outcomes, but their results are not consistent. A recent systematic review [13] and most [32, 33], but not all [34], observational studies favor the timely implementation of anti-influenza vaccination to prevent AMI incidence. In addition to primary prevention, anti-influenza vaccination has been reported as an effective preventive measure in patients with already established CAD [35]. Other researchers have argued that there is little or even no effect of anti-influenza vaccination on cardiovascular diseases-related hospital admissions [36, 37]. According to them, vaccination favorable effect on hospitalization rate is modest and only confined in the prevention of respiratory infection. From the vaccine perspective, selection bias, variation of influenza seasons' duration and unmeasured confounders might have affected the final results.

Regarding those controversies, the largest international scientific societies have considered the magnitude of data as robust evidence of annual anti-influenza vaccination for secondary, but not primary, prevention in patients with cardiovascular diseases, like those with CAD or HF [38, 39]. As a secondary prevention measure, anti-influenza vaccination may be considered in type 2 diabetic patients with a higher predisposition to cardiovascular diseases [40]. Notably, admissions for HF were significantly reduced in the flu season in vaccine recipients compared to those who did not receive the vaccine. Focusing on patients with HF, anti-influenza vaccination has the potential to modify the pathophysiologic mechanisms of HF (Fig. 1). However, current data supporting the preemptive implementation of anti-influenza vaccination to primarily prevent the de novo CHF development are missing.

\section{Anti-influenza vaccination in patients with pre-existed heart failure}

The advocacy of anti-influenza vaccination in HF is based on limited number of large, observational studies. There are additional data derived from population-based registries (Table 1). Methodological issues prevent an adequate response to the question of how effectively vaccination does prevent ADHF. Some studies have recorded higher hospitalization rates [46] and longer hospital stays [17] in unvaccinated patients with HF exacerbations. Those effects were more pronounced among elderly and patients with chronic kidney disease [47]. Despite the clinical relevance of those findings, they are based on AHF reports as reasons of hospital admission, without examining quantitative data about myocardial function prior to the event.

To address that question, a previous observational, population-based study examined the clinical impact of antiinfluenza vaccination on patients with diagnosis of CAD and/ 
Table 1 Summarized list of studies concerning the effects of influenza vaccination on clinical outcomes in patients with pre-existed heart failure

\begin{tabular}{|c|c|c|c|}
\hline Source & $\begin{array}{l}\text { Study design/number } \\
\text { of subjects }\end{array}$ & Vaccination/follow-up & Results of vaccination \\
\hline $\begin{array}{l}\text { De Diego C et al. (2009) } \\
\text { [31] }\end{array}$ & $\begin{array}{l}\text { Observational, } \\
\text { community-based } \\
\text { study/1340 Spanish pts., } \\
\geq 65 \text {-year-olds with chronic } \\
\text { heart } \\
\text { disease (congestive HF or } \\
\text { CAD) }\end{array}$ & $\begin{array}{l}480 \text { annually vaccinated pts. } \\
\text { vs. } 860 \text { non-vaccinated pts. } \\
\text { FU: } 40 \text { months }\end{array}$ & $\begin{array}{l}\downarrow \text { All-cause mortality throughout } \\
\text { the overall influenza periods } \\
\text { (January-April) compared } \\
\text { to the reference non-influenza } \\
\text { periods (June-September) } \\
\text { (adjusted HR: } 0.63 ; 95 \% \\
\text { CI: } 0.44-0.91 ; p=0.013 \text { ) } \\
\leftrightarrow \text { All-cause mortality during } \\
\text { the reference non-influenza } \\
\text { period (adjusted HR: } 0.94 ; \\
\text { 95\% CI: } 0.56-1.58 ; p=0.814 \text { ). }\end{array}$ \\
\hline Liu IF et al. (2012) [41] & $\begin{array}{l}\text { Observational } \\
\text { population-based } \\
\text { study/5048 Taiwanese } \\
\text { elderly pts. with ischemic } \\
\text { heart disease (HF, past } \\
\text { MI, CAD) }\end{array}$ & $\begin{array}{l}2760 \text { vaccinated pts. vs. } \\
2288 \text { non-vaccinated pts. } \\
\text { FU: } 4 \text { years }\end{array}$ & $\begin{array}{l}\text { During influenza season: } \\
\downarrow \text { All-cause mortality (HR: } 0.42 \text {; } \\
\text { 95\% CI: } 0.35-0.49 \text { ) } \\
\downarrow \text { Hospitalization for CVD } \\
\quad \text { (HR: } 0.84 ; 95 \% \text { CI: } 0.76-0.93 \text { ) } \\
\text { In the whole year: } \\
\downarrow \text { All-cause mortality } \\
\quad \text { (HR: } 0.78 ; 95 \% \text { CI: } 0.68-0.90 \text { ) }\end{array}$ \\
\hline $\begin{array}{l}\text { Mohseni H et al. (2016) } \\
\text { [42] }\end{array}$ & $\begin{array}{l}\text { Self-controlled case series from } \\
\text { the primary care database in } \\
\text { UK/59,202 HF pts. }\end{array}$ & $\begin{array}{l}\text { Within person comparison: an } \\
\text { influenza vaccination in any } \\
\text { subsequent year vs. an adjacent } \\
\text { vaccination-free year } \\
\text { (before or after). } \\
\text { FU: } 2 \text { consecutive years }\end{array}$ & $\begin{array}{l}\downarrow \text { Hospitalizations due to CVD } \\
\quad \text { (incident rate ratio: } 0.73 ; 95 \% \mathrm{CI} \text { : } \\
0.71-0.76 \text { ) } \\
\downarrow \text { Hospitalizations due to all-causes } \\
\quad \text { (incident rate ratio: } 0.96 \text {; } 95 \% \text { CI: } \\
\quad 0.95-0.98 \text { ) }\end{array}$ \\
\hline Kopel E et al. (2014) [43] & $\begin{array}{l}\text { Heart Failure Survey in Israel } \\
\text { (HFSIS), prospective study/ } \\
1964 \text { pts. hospitalized with } \\
\text { acute HF }\end{array}$ & $\begin{array}{l}501 \text { vaccinated pts. vs. } 1453 \\
\text { non-vaccinated pts. } \\
\text { FU: End of each hospitalization, } 1 \text { and } 4 \text { years }\end{array}$ & $\begin{array}{l}\downarrow 1 \text {-year all-cause mortality } \\
\quad \text { (HR: } 0.81 ; 95 \% \text { CI: } 0.66-0.99 \text {, } \\
p=0.004 \text { ) } \\
\downarrow 4 \text {-year all-cause mortality } \\
\quad \text { (HR: } 0.83 \text {; 95\%CI: } 0.73-0.95 \text {, } \\
\quad p=0.006 \text { ) }\end{array}$ \\
\hline $\begin{array}{l}\text { PARADIGM-HF (2016) } \\
\text { [44] }\end{array}$ & $\begin{array}{l}\text { Sub-analysis of } \\
\text { PARADIGM-HF } \\
\text { trial: randomly allocated } \\
\text { to sacubitril/valsartan or } \\
\text { enalapril/8399 symptomatic, } \\
\text { HF pts. with reduced EF } \\
(<40 \%)\end{array}$ & $\begin{array}{l}1769 \text { vaccinated pts. vs. } 6630 \\
\text { non-vaccinated pts. Vaccination } \\
12 \text { months prior to study entrance. } \\
\text { FU: } 12 \text { months post-randomization }\end{array}$ & $\begin{array}{l}\downarrow \text { All-cause mortality (HR: } 0.81 \text {; } \\
\text { 95\% CI: } 0.67-0.97 ; p=0.015 \text { ). } \\
\uparrow \text { Rates of cardiopulmonary, } \\
\text { influenza-related, and all-cause } \\
\text { hospitalization in unadjusted } \\
\text { models, but not in } \\
\text { propensity-adjusted models }\end{array}$ \\
\hline Wu WC et al. (2014) [45] & $\begin{array}{l}\text { Retrospective analysis/ } \\
2739 \text { HF pts. treated in } \\
\text { Veterans Health } \\
\text { Administration Hospitals }\end{array}$ & $\begin{array}{l}2087 \text { vaccinated pts. (before or during } \\
\text { admission) vs. } 429 \text { non-vaccinated pts. } \\
\text { FU: up to } 1 \text { year }\end{array}$ & $\begin{array}{l}\downarrow 30 \text {-day adjusted all-cause } \\
\text { mortality (OR: } 0.49 ; 95 \% \text { CI: } \\
0.29-0.83 \text { ) } \\
\downarrow 1 \text {-year adjusted all-cause mortality } \\
\quad \text { (OR: } 0.74 ; 95 \% \text { CI: } 0.58-0.96 \text { ) }\end{array}$ \\
\hline
\end{tabular}

$R A A S$ renin-angiotensin-aldosterone system; $S N S$ sympathetic nervous system, $L V$ left ventricle, $H R$ hazard ratio, $F U$ follow-up, $y r$ years, $C I$ confidence interval, $C V D$ cardiovascular disease, $C A D$ coronary artery disease, $H F$ heart failure, pts. patients, $O R$ odd ratio, $E F$ ejection fraction, $S O L V D$ Studies of Left Ventricular Dysfunction,

or ischemic HF [41]. There was an independent association of vaccination with reduced risk of heart disease-related hospitalizations only during influenza seasons. Another community-based study demonstrated reduced all-cause mortality only throughout the influenza periods (January-April) in four consecutive years in Spanish patients with congestive HF or CAD who received annual anti-influenza vaccination [31]. Most recently, Mohseni et al. (2017) [42], using a selfcontrolled case series design, demonstrated the association of anti-influenza vaccination with reduced hospitalization risk, especially for cardiovascular diseases, in 59,202 HF patients. Additional data underpinned reduced hospitalization rate and survival benefits, not only during influenza seasons, but persistently in the whole year in vaccinated HF patients $[39,43]$. Although the favorable results of vaccination were independent of several confounders, none of the above studies was powered to prove cause-effect relationship between vaccination and survival. Presumably, unmeasured confounding 
factors and bias, like the co-existence of higher medical surveillance and socioeconomic status in vaccinated patients, may explain their improved survival.

A sub-analysis of the large-scale PARADIGM-HF trial was recently published [44]. The main aim of PARADIGM-HF trial was the comparative evaluation of LCZ696 (sacubitril/ valsartan) and enalapril in patients with symptomatic HF and reduced $\mathrm{EF}(<40 \%)$. That sub-analysis revealed lower risk for all-cause mortality in vaccine recipients compared to the nonvaccinated group. Although influenza vaccination did not affect the superior clinical benefits of LCZ696 over enalapril during the follow-up period (median duration: 27 months), vaccine remained an independent determinant of survival in the propensity-adjusted models. A negative effect of vaccine implementation in that trial was the higher risk for all-cause hospitalization. However, that risk was blunted after propensity adjustment, implicating common confounders. All the above results should be cautiously evaluated to extrapolate conclusions [48]. Firstly, the published sub-analysis collected data from the PARADIGM-HF trial database that was not originally designed to assess the effectiveness of antiinfluenza vaccination; thus residual confounding is a major issue in proving direct vaccination effects. Secondly, it was a multi-center, international trial recruiting patients from different health systems with diverse compliance to guidelines. That was depicted by the wide variety of vaccination rates along different countries (from 0 to $77.5 \%$ ), leading to an extremely low overall prescription rate of vaccine $(21 \%)$. In developed countries the vaccination rate was higher, probably because their residents had easier access to high quality healthcare services. The latter phenomenon could explain either the higher trend for hospitalization or the reduced mortality observed in vaccinated group. On the other hand, unvaccinated patients mostly originated from undeveloped countries and used life-saving therapeutic modalities (e.g., b-blockers, ICDs etc) at a much lower frequency; this might have influenced the final results.

In terms of effectiveness, anti-influenza vaccination seems to reduce HF-related hospitalizations and all-cause mortality, especially during influenza periods, in patients with preexisted HF.

\section{High dose versus standard dose of vaccination in heart failure}

The vaccine effectiveness relies upon intact immune responses, which may be compromised in HF. Following influenza immunization most individuals develop both antibody titers and T-cell immune responses. The efficacy (laboratory measured) and consequently the effectiveness (clinical outcomes) of anti-influenza vaccine seem to decrease with increasing age and the presence of co-morbidities [49]. Evidence derived from small previous studies in HF patients suggests waning humoral-mediated [50] and T-cell [51] immunity response to vaccination compared to healthy controls. Albrecht CM et al. (2014) [52] observed a significant decline of mean antibody titers to both the $\mathrm{A} / \mathrm{H} 3 \mathrm{~N} 2$ and $\mathrm{A} / \mathrm{H} 1 \mathrm{~N} 1$ influenza strains over a 12-month post-vaccination period in HF patients compared to healthy controls.

A more aggressive approach of vaccination using high rather than standard-dose vaccine in elderly patients has been proposed [53]. Notably, a recently published randomized, double-blind, active-controlled efficacy trial in 31,989 medically stable adults aged $>65$ years, documented the superiority of four-fold dose over standard dose in reducing the incidence of influenza caused by any viral type or subtype [49]. In the same study, which included patients with stable HF and/or $\mathrm{CAD}$, high-dose vaccine recipients showed lower rates for pneumonia, cardiorespiratory disturbances, and medications prescription. All those clinical data were not comparatively evaluated with anti-bodies titers. A small, pilot, randomized, double-blind, active-controlled study investigated the double dose versus standard dose of influenza vaccination among 28 patients with HF [54]. The double dose group appeared with more vigorous (within 2-4 weeks post-vaccination) response with higher antibody titers to $\mathrm{A} / \mathrm{H} 3 \mathrm{~N} 2, \mathrm{~A} / \mathrm{H} 1 \mathrm{~N} 1$, and B-type influenza antigens. The absolute antibody titers remained above seroprotective levels, but the difference between groups was eliminated after 4-6 months. The authors commented the higher initial antibody titers as a promising sign of higher degree protection against influenza infection. However, these preliminary data were based on a small sample and the clinical relevance of antibody titers alterations is doubtful [55]. Concerning the reduced immune response in patients with even mild HF, unambiguously, further large studies are necessary to draw firm conclusions about the appropriate and safe dose of anti-influenza vaccine provided that no substantial drift exists.

\section{Anti-influenza vaccination safety and timing in heart failure patients}

Despite the previously mentioned overwhelming evidence of the burden of influenza and the high effectiveness of antiinfluenza vaccine, the fear of negative side effects has discouraged many people from getting vaccinated. Evidence deriving from the general population has failed to show an association between influenza vaccines and significant side effects [56, 57]. Given the acceptable safety profile of influenza vaccines and the World Health Organization's recommendation for its use in high-risk populations, influenza immunization seems to be a cost-effective and safe approach to decrease influenza burden in $\mathrm{HF}$.

Influenza vaccines confer only short-lived, strain-specific immunity, and annual revaccination is required. Optimal timing is difficult to predict, since the influenza season starts 
at different times each year and influenza activity may vary among geographic regions. In clinical practice, the administration of anti-influenza vaccine in HF patients is wise to take place in pre-influenza seasons (prior to winter), with renewed formulation each time. Interestingly, a large retrospective study in male veterans admitted to hospitals due to HF underpinned the survival benefits of anti-influenza vaccination not only among patients vaccinated before, but also during hospitalization [45]. Thereby, the authors recommended vaccination of HF patients even as part of in-hospital practice settings.

\section{Future implication of vaccination in heart failure}

The majority of large studies have enrolled communitydwelling populations with mixed characteristics (e.g., heart or lung diseases), where it is difficult to distinguish HF patients. Moreover, HF is mostly referred as the admission reason for patients with concomitant influenza infection, while only a limited number of studies have clearly defined cohorts with pre-existed HF. Hence, the future research should point towards populations with established HF. Details of pre- and post-infection clinical characteristics and medications records are necessary in order to retrieve the pure effect of antiinfluenza vaccination on HF progression and precisely assess the incidence of HF decompensation. It would be also prudent to evaluate the vaccination effects along the classes of HF severity. Another important drawback of observational studies and meta-analyses is the difficulties to evaluate classify a death as influenza-related mortality. For this purpose, most researchers have presented results on all-cause mortality instead of specific-cause mortality. Therefore, a residual confounding in the estimates of vaccine effectiveness cannot be entirely excluded.

According to prevailing recommendations, the antiinfluenza vaccination should be encouraged in HF patients, who are at high mortality risk. Unfortunately, they often have suboptimum vaccine uptake. A significant proportion of elderly people with chronic HF remain annually unvaccinated against influenza [31, 44]. A plethora of factors like beliefs, attitudes and opinions of patients and health professionals, socioeconomic and educational conditions, race minorities, and vaccination during previous years may act as obstacles to sustain vaccination programs. Another important determinant of vaccination implementation is the management of healthcare systems. Only well-organized national and international campaigns, based on robust evidence, may boost vaccination in routine practice. Most European countries still remain well below the $75 \%$ proposed coverage threshold for people older than 65 years or patients with high-risk conditions.
Large-scale and adequately powered studies targeting the effectiveness and safety of anti-influenza vaccination will assess beyond any doubt the cost-effectiveness of anti-influenza vaccination in HF patients (secondary prevention) or those at increased risk for HF development (primary prevention).

\section{Conclusion}

Seasonal influenza infection, especially among elderly populations, is associated with high occurrence of AHF, increased cardiovascular morbidity and all-cause mortality. Based on data from the general population, annual anti-influenza vaccination seems to be an effective measure to prevent AHF episodes and in some degree to improve survival. Confining literature research in patients with pre-existed HF, there are limited data favoring the incorporation of anti-influenza vaccination as an adjunctive therapy, to reduce hospitalizations and all-cause mortality rates. Unambiguously, future studies will verify the required dose and the potential benefits and risks of annual anti-influenza vaccination in the context of primary prevention or standard care processes of established HF (like medications, LV function assessment, etc).

Acknowledgements Nikolaos Kadoglou was granted as a clinical fellow by the European Heart Rhythm Association.

\section{Compliance with ethical standards}

Conflict of interest The authors declare that they have no conflict of interest.

Open Access This article is distributed under the terms of the Creative Commons Attribution 4.0 International License (http:// creativecommons.org/licenses/by/4.0/), which permits unrestricted use, distribution, and reproduction in any medium, provided you give appropriate credit to the original author(s) and the source, provide a link to the Creative Commons license, and indicate if changes were made.

\section{References}

1. Ryu SW, Lee JH, Kim J, Jang MA, Nam JH, Byoun MS, Lim CS (2016) Comparison of two new generation influenza rapid diagnostic tests with instrument-based digital readout systems for influenza virus detection. Br J Biomed Sci 21:1-6

2. Breen M, Nogales A, Baker SF, Perez DR, Martínez-Sobrido L (2016) Replication-competent influenza A and B viruses expressing a fluorescent dynamic timer protein for in vitro and in vivo studies. PLoS One 1:e0147723

3. Oshansky CM, Wong SS, Jeevan T, Smallwood HS, Webby RJ, Shafir SC, Thomas PG (2014) Seasonal influenza vaccination is the strongest correlate of cross-reactive antibody responses in migratory bird handlers. MBio 5:e2107

4. World Health Organization (2014) Fact sheet on influenza. http:// www.who.int/mediacentre/factsheets/fs211/en/ 
5. Brendish NJ, Schiff HF, Clark TW (2015) Point-of-care testing for respiratory viruses in adults: the current landscape and future potential. J Inf Secur 71:501-510

6. Nguyen JL, Yang W, Ito K, Matte TD, Shaman J, Kinney PL (2016) Seasonal influenza infections and cardiovascular disease mortality. JAMA Cardiol 1:274-281

7. Nicholson KG (1998) Human influenza. In: Nicholson KG, Webster RG, Hay AJ (eds) Textbook of influenza. Blackwell Science, Oxford, pp 219-264

8. Bramley AM, Dasgupta S, Skarbinski J, Kamimoto L, Fry AM, Finelli L, Jain S (2012) Pandemic influenza A (H1N1) virus hospitalizations investigation team. Intensive care unit patients with 2009 pandemic influenza A (H1N1pdm09) virus infection-United States, 2009. Influenza Other Respir Viruses 6:e134-e142

9. Smith AM (2017) Quantifying the therapeutic requirements and potential for combination therapy to prevent bacterial coinfection during influenza. J Pharmacokinet Pharmacodyn 44:81-93

10. Cromer D, van Hoek AJ, Jit M, Edmunds WJ, Fleming D, Miller E (2014) The burden of influenza in England by age and clinical risk group: a statistical analysis to inform vaccine policy. J Inf Secur 68: 363-371

11. Corrales-Medina VF, Alvarez KN, Weissfeld LA, Angus DC, Chirinos JA, Chang CC, Newman A, Loehr L, Folsom AR, Elkind MS, Lyles MF, Kronmal RA, Yende S (2015) Association between hospitalization for pneumonia and subsequent risk of cardiovascular disease. JAMA 313:264-274

12. Warren-Gash C, Smeeth L, Hayward AC (2009) Influenza as a trigger for acute myocardial infarction or death from cardiovascular disease: a systematic review. Lancet Infect Dis 9:601-610

13. Barnes M, Heywood AE, Mahimbo A, Rahman B, Newall AT, Macintyre CR (2015) Acute myocardial infarction and influenza: a meta-analysis of case-control studies. Heart 101:1738-1747

14. Dick SA, Epelman S (2016) Chronic heart failure and inflammation: what do we really know? Circ Res 119:159-176

15. Fagnoul D, Pasquier P, Bodson L, Ortiz JA, Vincent JL, De Backer D (2013) Myocardial dysfunction during H1N1 influenza infection. J Crit Care 28:321-327

16. Ludwig A, Lucero-Obusan C, Schirmer P, Winston C, Holodniy M (2015) Acute cardiac injury events $\leq 30$ days after laboratoryconfirmed influenza virus infection among U.S. veterans, 2010 2012. BMC Cardiovasc Disord. 15:109.

17. Marti CN, Georgiopoulou VV, Kalogeropoulos AP (2013) Acute heart failure: patient characteristics and pathophysiology. Curr Heart Fail Rep. 10:427-433

18. Tomiyama H, Yamashina A (2015) Vascular dysfunction: a key player in chronic cardio-renal syndrome. Intern Med 54:1465-1472

19. Ponikowski P, Voors AA, Anker SD, Bueno H, Cleland JG, Coats AJ, Falk V, González-Juanatey JR, Harjola VP, Jankowska EA, Jessup M, Linde C, Nihoyannopoulos P, Parissis JT, Pieske B, Riley JP, Rosano GM, Ruilope LM, Ruschitzka F, Rutten FH, van der Meer P, Authors/Task Force Members; Document Reviewers (2016) ESC Guidelines for the diagnosis and treatment of acute and chronic heart failure: the Task Force for the diagnosis and treatment of acute and chronic heart failure of the European Society of Cardiology (ESC). Developed with the special contribution of the Heart Failure Association (HFA) of the ESC. Eur J Heart Fail 18: 891-975

20. Patel NJ, Nalluri N, Deshmukh A, Pant S, Shah N, Badheka AO, Asti D, Lafferty JC, Schwartz C (2014) Seasonal trends of heart failure hospitalizations in the United States: a national perspective from 2000 to 2011. Int J Cardiol 173:562-563

21. Sandoval C, Walter SD, Krueger P, Smieja M, Smith A, Yusuf S, Loeb MB (2007) Risk of hospitalization during influenza season among a cohort of patients with congestive heart failure. Epidemiol Infect 135:574-582
22. Xu B, Liu H, Su N, Kong G, Bao X, Li J, Wang J, Li Y, Ma X, Zhang J, Yu GP, Zhao L (2013) Association between winter season and risk of death from cardiovascular diseases: a study in more than half a million inpatients in Beijing. China BMC Cardiovasc Disord 13:93

23. Godoy HL, Silveira JA, Segalla E, Almeida DR (2011) Hospitalization and mortality rates for heart failure in public hospitals in São Paulo. Arq Bras Cardiol 97:402-407

24. Colombo PC, Ganda A, Lin J, Onat D, Harxhi A, Iyasere JE, Uriel N, Cotter G (2012) Inflammatory activation: cardiac, renal, and cardio-renal interactions in patients with the cardio-renal syndrome. Heart Fail Rev 17:177-190

25. Colombo PC, Doran AC, Onat D, Wong KY, Ahmad M, Sabbah HN, Demmer RT (2015) Venous congestion, endothelial and neurohormonal activation in acute decompensated heart failure: cause or effect? Curr Heart Fail Rep. 12:215-222

26. Ganda A, Onat D, Demmer RT, Wan E, Vittorio TJ, Sabbah HN, Colombo PC (2010) Venous congestion and endothelial cell activation in acute decompensated heart failure. Curr Heart Fail Rep 7: 66-74

27. Chang DH, Bednarczyk RA, Becker ER, Hockenberry JM, Weiss PS, Orenstein WA, Omer SB (2016) Trends in U.S. hospitalizations and inpatient deaths from pneumonia and influenza, 1996-2011. Vaccine 34:486-494

28. Wang CS, Wang ST, Lai CT, Lin LJ, Lee CT, Chou P (2004) Reducing major cause-specific hospitalization rates and shortening hospital stays after influenza vaccination. Clin Infect Dis 39:1604 1610

29. Ridenhour BJ, Campitelli MA, Kwong JC, Rosella LC, Armstrong BG, Mangtani P, Calzavara AJ, Shay DK (2013) Effectiveness of inactivated influenza vaccines in preventing influenza-associated deaths and hospitalizations among Ontario residents aged $\geq 65$ years: estimates with generalized linear models accounting for healthy vaccinee effects. PLoS One 8:e76318

30. Nichol KL, Nordin JD, Nelson DB, Mullooly JP, Hak E (2007) Effectiveness of influenza vaccine in the community-dwelling elderly. N Engl J Med 357:1373-1381

31. de Diego C, Vila-Córcoles A, Ochoa O, Rodriguez-Blanco T, Salsench E, Hospital I, Bejarano F, Del Puy Muniain M, Fortin M, Canals M, EPIVAC Study Group (2009) Effects of annual influenza vaccination on winter mortality in elderly people with chronic heart disease. Eur Heart J 30:209-216

32. Gwini SM, Coupland CA, Siriwardena AN (2011) The effect of influenza vaccination on risk of acute myocardial infarction: selfcontrolled case-series study. Vaccine 29:1145-1149

33. Macintyre CR, Heywood AE, Kovoor P, Ridda I, Seale H, Tan T, Gao Z, Katelaris AL, Siu HW, Lo V, Lindley R, Dwyer DE (2013) Ischaemic heart disease, influenza and influenza vaccination: a prospective case control study. Heart 99:1843-1848

34. Heffelfinger JD, Heckbert SR, Psaty BM, Weiss NS, Thompson WW, Bridges CB, Jackson LA (2006) Influenza vaccination and risk of incident myocardial infarction. Hum Vaccin. 2:161-166

35. Clar C, Oseni Z, Flowers N, Keshtkar-Jahromi M, Rees K (2015) Influenza vaccines for preventing cardiovascular disease. Cochrane Database Syst Rev 5:CD005050

36. Baxter R, Ray GT, Fireman BH (2010) Effect of influenza vaccination on hospitalizations in persons aged 50 years and older. Vaccine 28:7267-7272

37. Arriola CS, Anderson EJ, Baumbach J, Bennett N, Bohm S, Hill M, Lindegren ML, Lung K, Meek J, Mermel E, Miller L, Monroe ML, Morin C, Oni O, Reingold A, Schaffner W, Thomas A, Zansky SM, Finelli L, Chaves SS (2015) Does influenza vaccination modify influenza severity? Data on older adults hospitalized with influenza during the 2012-2013 season in the United States. J Infect Dis 212: $1200-1208$ 
38. Davis MM, Taubert K, Benin AL, Brown DW, Mensah GA, Baddour LM, Dunbar S, Krumholz HM, American Heart Association, American College of Cardiology, American Association of Cardiovascular and Pulmonary Rehabilitation, American Association of Critical Care Nurses, American Association of Heart Failure Nurses, American Diabetes Association, Association of Black Cardiologists, Inc, Heart Failure Society of America, Preventive Cardiovascular Nurses Association, American Academy of Nurse Practitioners, Centers for Disease Control and Prevention and the Advisory Committee on Immunization (2006) Influenza vaccination as secondary prevention for cardiovascular disease: a science advisory from the American Heart Association/American College of Cardiology. J Am Coll Cardiol 48:1498-1502

39. Members TF, Montalescot G, Sechtem U, Achenbach S, Andreotti F, Arden C, Budaj A, Bugiardini R, Crea F, Cuisset T, Di Mario C, Ferreira JR, Gersh BJ, Gitt AK, Hulot JS, Marx N, Opie LH, Pfisterer M, Prescott E, Ruschitzka F, Sabaté M, Senior R, Taggart DP, van der Wall EE, Vrints CJ, ESC Committee for Practice Guidelines, Zamorano JL, Achenbach S, Baumgartner H, Bax JJ, Bueno H, Dean V, Deaton C, Erol C, Fagard R, Ferrari R, Hasdai D, Hoes AW, Kirchhof P, Knuuti J, Kolh P, Lancellotti P, Linhart A, Nihoyannopoulos P, Piepoli MF, Ponikowski P, Sirnes PA, Tamargo JL, Tendera M, Torbicki A, Wijns W, Windecker S, Reviewers D, Knuuti J, Valgimigli M, Bueno H, Claeys MJ, Donner-Banzhoff N, Erol C, Frank H, Funck-Brentano C, Gaemperli O, Gonzalez-Juanatey JR, Hamilos M, Hasdai D, Husted S, James SK, Kervinen K, Kolh P, Kristensen SD, Lancellotti P, Maggioni AP, Piepoli MF, Pries AR, Romeo F, Rydén L, Simoons ML, Sirnes PA, Steg PG, Timmis A, Wijns W, Windecker S, Yildirir A, Zamorano JL (2013) ESC guidelines on the management of stable coronary artery disease: the Task Force on the management of stable coronary artery disease of the European Society of Cardiology. Eur Heart J 34:2949-3003

40. Vamos EP, Pape UJ, Curcin V, Harris MJ, Valabhji J, Majeed A, Millett C (2016) Effectiveness of the influenza vaccine in preventing admission to hospital and death in people with type 2 diabetes. CMAJ 188:E342-E351

41. Liu IF, Huang CC, Chan WL, Huang PH, Chung CM, Lin SJ, Chen JW, Leu HB (2012) Effects of annual influenza vaccination on mortality and hospitalization in elderly patients with ischemic heart disease: a nationwide population-based study. Prev Med 54:431-433

42. Mohseni H, Kiran A, Khorshidi R, Rahimi K (2017) Influenza vaccination and risk of hospitalization in patients with heart failure: a self-controlled case series study. Eur Heart J 38:326-333

43. Kopel E, Klempfner R, Goldenberg I (2014) Influenza vaccine and survival in acute heart failure. Eur J Heart Fail 16:264-270

44. Vardeny O, Claggett B, Udell JA, Packer M, Zile M, Rouleau J, Swedberg K, Desai AS, Lefkowitz M, Shi V, McMurray JJ, Solomon SD, Investigators PARADIGM-HF (2016) Influenza vaccination in patients with chronic heart failure: the PARADIGM-HF trial. JACC Heart Fail. 4:152-158
45. Wu WC, Jiang L, Friedmann PD, Trivedi A (2014) Association between process quality measures for heart failure and mortality among US veterans. Am Heart J 168:713-720

46. Nichol KL, Nordin J, Mullooly J, Lask R, Fillbrandt K, Iwane M (2003) Influenza vaccination and reduction in hospitalizations for cardiac disease and stroke among the elderly. N Engl J Med 348: 1322-1332

47. Fang YA, Chen CI, Liu JC, Sung LC (2016) Influenza vaccination reduces hospitalization for heart failure in elderly patients with chronic kidney disease: a population-based cohort study. Acta Cardiol Sin 32:290-298

48. Acharya D, Uyeki TM (2016) The PARADIGM of influenza vaccination in heart failure patients. JACC Heart Fail 4:159-161

49. Liu WM, van der Zeijst BA, Boog CJ, Soethout EC (2011) Aging and impaired immunity to influenza viruses: implications for vaccine development. Hum Vaccin 7(Suppl):94-98

50. Vardeny O, Sweitzer NK, Detry MA, Moran JM, Johnson MR, Hayney MS (2009) Decreased immune responses to influenza vaccination in patients with heart failure. J Card Fail 15:368-373

51. Vardeny O, Moran JJ, Sweitzer NK, Johnson MR, Hayney MS (2010) Decreased T-cell responses to influenza vaccination in patients with heart failure. Pharmacotherapy 30:10-16

52. Albrecht CM, Sweitzer NK, Johnson MR, Vardeny O (2014) Lack of persistence of influenza vaccine antibody titers in patients with heart failure. J Card Fail 20:105-109

53. DiazGranados CA, Dunning AJ, Kimmel M, Kirby D, Treanor J, Collins A, Pollak R, Christoff J, Earl J, Landolfi V, Martin E, Gurunathan S, Nathan R, Greenberg DP, Tornieporth NG, Decker MD, Talbot HK (2014) Efficacy of high-dose versus standard-dose influenza vaccine in older adults. N Engl J Med 371:635-645

54. Van Ermen A, Hermanson MP, Moran JM, Sweitzer NK, Johnson MR, Vardeny O (2013) Double dose vs. standard dose influenza vaccination in patients with heart failure: a pilot study. Eur J Heart Fail 15:560-564

55. Yao X, Hamilton RG, Weng NP, Xue QL, Bream JH, Li H, Tian J, Yeh SH, Resnick B, Xu X, Walston J, Fried LP, Leng SX (2011) Frailty is associated with impairment of vaccine-induced antibody response and increase in post-vaccination influenza infection in community-dwelling older adults. Vaccine 29:5015-5021

56. Black S, Eskola J, Siegrist CA, Halsey N, Macdonald N, Law B, Miller E, Andrews N, Stowe J, Salmon D, Vannice K, Izurieta HS, Akhtar A, Gold M, Oselka G, Zuber P, Pfeifer D, Vellozzi C (2009) Importance of background rates of disease in assessment of vaccine safety during mass immunisation with pandemic H1N1 influenza vaccines. Lancet 374:2115-2122

57. Kawai AT, Li L, Kulldorff M, Vellozzi C, Weintraub E, Baxter R, Belongia EA, Daley MF, Jacobsen SJ, Naleway A, Nordin JD, Lee GM (2014) Absence of associations between influenza vaccines and increased risks of seizures, Guillain-Barré syndrome, encephalitis, or anaphylaxis in the 2012-2013 season. Pharmacoepidemiol Drug Saf 23:548-553 